\title{
A esquistossomose e o Nordeste semi-árido, I - O estudo preliminar *
}

\author{
Dirceu P. Pereira da Costa*" \\ Frederico Simões Barbosa ***
}

An epidemiological survey was made on the inhabitants of 23 artificial dams constructed by D.N.O.C.S.,

Northeastern Brazil. Nine autocthonous cases of

schistosomiasis were found in irrigated areas located in São Gonçalo (state of Paraiba) where this endemic disease was already known. Other two cases were found in the irrigated area of Moxotó (state of Pernambuco).

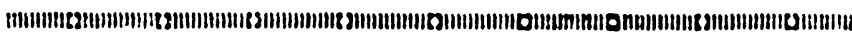

O Polígono das Secas, definido oficialmente pelo Governo Federal em 1958, compreende cerca de $950.000 \mathrm{~km}^{2}$, sejam $58 \%$ do Nordeste e $12 \%$ do território nacional. A escassez e a irregularidade das chuvas são as mais marcantes de suas características.

Esta extensa região do país está longe de ser uniforme, mesmo quando se a encara sob o ponto de vista pluviométrico. As temperaturas elevadas, com pequenas variações, alcançam médias anuais entre 23 e $37^{\circ} \mathrm{C}$. Valores de 2.800 horas/ano indicam o grau de insolação predominante na região.

A monografia editada pelo $\mathrm{CNPq}^{3}$ resume os principais dados sobre a região do semi-árido. Esta região, como entendida pela SUDENE, tem $1.671 .000 \mathrm{~km}^{2}$, compreenden. do nove Estados, do Maranhão ao Norte de Minas Gerais, e o Território de Fernando de Noronha.

$O$ presente trabalho resultou de recomendações incluídas no relatório do grupo de trabalho sobre Epidemiologia e Controle da Esquistossomose no Nordeste Semi-Árido, promovido pelo programa do Trópico Semi-Árido (CNPq), em Recife ${ }^{3}$.

O objetivo geral do projeto residiu no esclarecimento dos aspectos epidemiológicos da esquistossomose com vistas ao controle da endemia no Nordeste Semi-Árido, incluindose tanto os perímetros de irrigação como as grandes barragens.

O objetivo específico deste estudo preliminar foi o de promover o diagnóstico da situação dos perimetros de irri-
* Trabalho financiado, em parte, pelo Programa do Trópico Semi. Arido, CNPq.

* Centro de Pesquisas Aggeu Magalhäes - FIOCRUZ - Recife

*** Escola Nacional de Saúde Puiblica - FIOCRUZ - Rio de Janeiro 
gação, a fim de selecionar áreas para estudos de maior profundidade que serão publicados em continuação a este.

\section{METODOLOGIA}

A presente fase do estudo foi limitada às áreas de irrigação do DNOCS, nos Estados de Pernambuco, Paraíba, Rio Grande do Norte, Ceará e Piauí, compreendendo 23 perímetros de irrigação (mapa).

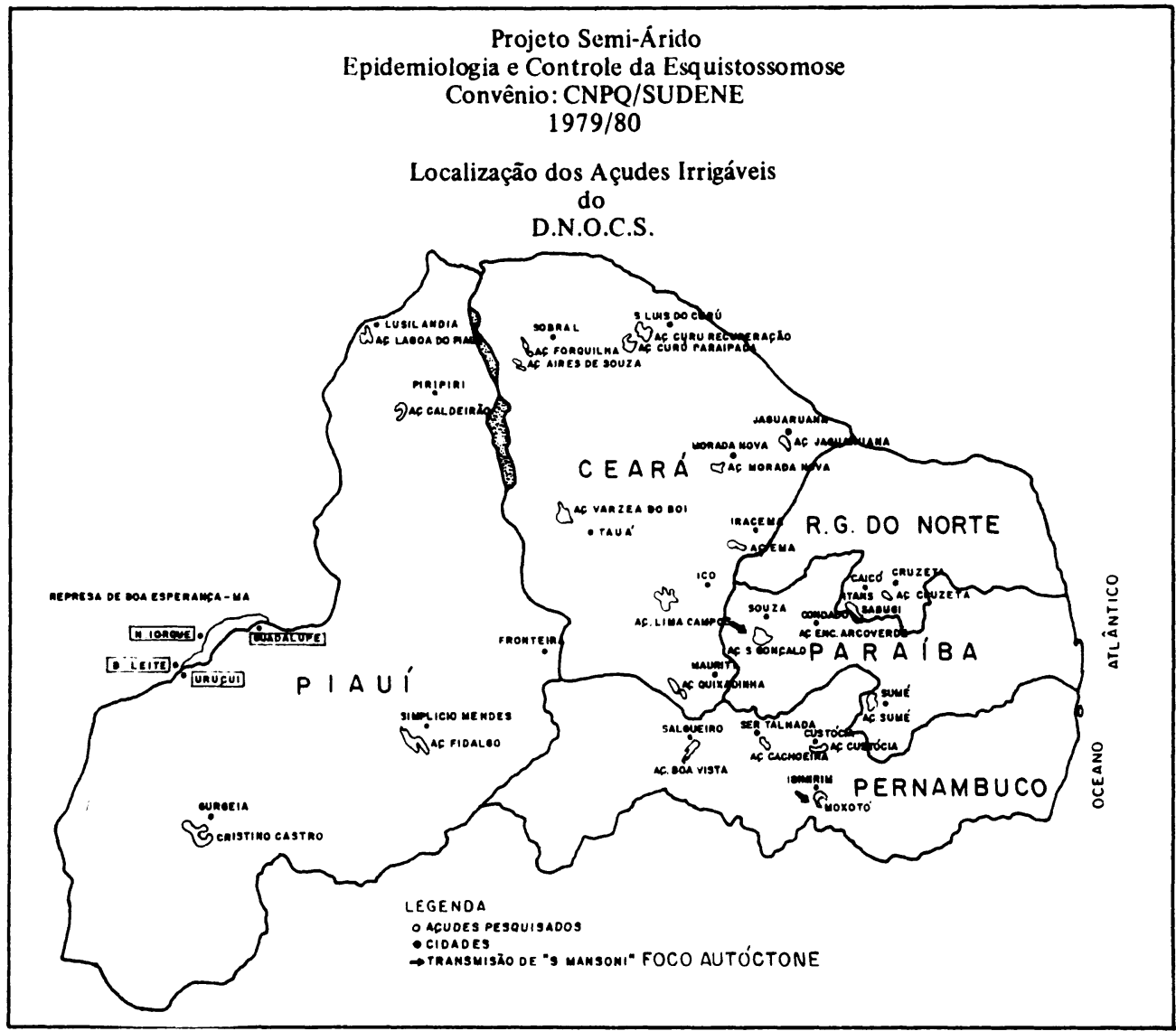

Nesta fase do trabalho, foi feito um estudo in loco cobrindo os Estados envolvidos, durante o periodo de janeiro a maio de 1979. Em cada perímetro de irrigação, foi aplicado um formulário que permitisse caracterizar a área em relação às seguintes condições: número de colonos, anos de operação, tipo de irrigação, localização da moradia, principais culturas, renda familiar e exame parasitológico das fezes, dentre outras. Estes formulários foram preenchidos por técnicos de pesquisa treinados para este fim. 
A seleção das áreas problemáticas foi feita pela escolha de sete áreas representativas, de acordo com os seguintes critérios:

1 - tipo de irrigação;

2 - tempo de operação do projeto;

3 - condições de vida das populações, como renda, localização de moradia, relações com focos de planorbídeos, tipos de cultura;

4 - presença de população flutuante;

5 - relações sociais de produção;

6 - informações prévias sobre a presença da esquistossomose;

7 - presença de transmissores de $S$. mansoni;

8 - número de colonos.

De fato, verificou-se que alguns destes itens eram comuns a todos os perímetros de irrigação, como os relacionados com a presença de população flutuante, as relações de produção e o transmissor encontrado.

A coleta do material fecal foi realizada nos domicílios dos colonos e encaminhada ao laboratório do Centro de Pesquisas Aggeu Magalhães, em Recife. O método utilizado foi o de Lutz para determinação dos índices de infecção humana das helmintoses intestinais, principalmente a esquistossomose. Nesta etapa, foram realizados 9.044 exames de fezes.

Com relação aos moluscos transmissores, foram pesquisados os criadouros localizados nos canais de irrigação, principalmente ao nível dos lotes dos colonos, ou nos canais de distribuição, onde a população humana tinha contato mais intimo com as águas poluídas.

A autoctonia da esquistossomose era seguramente conhecida apenas para o perímetro de São Gonçalo, PB, onde a SUCAM assinalou, em 1979, 40\% de infecção na área. *

Todos os perímetros de irrigação que mostraram positividade para $S$. mansoni foram selecionados para estudo de autoctonia. Para tal, cada caso foi entrevistado pelo Autor principal deste trabalho, considerando-se como autóctones apenas aquelas pessoas infectadas que nasceram no local ou área não-endêmica e que nunca estiveram em região endêmica da esquistossomose.

\section{RESULTADOS}

Os 23 perímetros de irrigação estudados no presente trabalho estão selecionados na Tabela I, de acordo com sua localização, população e os exames de fezes realizados com positividade para Schistosoma mansoni. O número de pessoas infectadas foi muito baixo em relação ao númeı de exames realizados.

* Informação obtida localmente. 
PESQUISA

\section{TABELA I}

Diagnóstico preliminar - exames coprológicos realizados de janeiro a maio de 1979 - perimetros irrigados do semi-árido, DNOCS

\begin{tabular}{|c|c|c|c|c|c|c|}
\hline Nọ & Perímetro & Município & Estado & $\begin{array}{l}\text { População } \\
\text { Aproximada }\end{array}$ & $\begin{array}{l}\text { Exame } \\
\text { Realizados }\end{array}$ & $\begin{array}{l}\text { de fezes } \\
\text { Positivos p/ } \\
\text { S. mansoni }\end{array}$ \\
\hline 01 & Cachoeira II & Serra Talhada & PE & 280 & 268 & - \\
\hline 02 & Boa Vista & Salgueiro & PE & 256 & 246 & - \\
\hline 03 & Custódia & Custódia & PE & 300 & 282 & - \\
\hline 04 & Moxotó & Ibimirim & PE & 1.160 & 702 & 04 \\
\hline 05 & Sumé & Sumé & PB & 380 & 359 & - \\
\hline 06 & Enge Arcoverde & Condado & PB & 330 & 315 & - \\
\hline 07 & São Gonçalo & Souza & PB & 1.800 & 552 & 14 \\
\hline 08 & Itans-Sabugi & Caicó & RN & 394 & 363 & 03 \\
\hline 09 & Cruzeta & Cruzeta & RN & 140 & 168 & - \\
\hline 10 & Várzea do Boi & Tauá & $\mathrm{CE}$ & 500 & 323 & - \\
\hline 11 & Lima Campos & Icó & $\mathrm{CE}$ & 2.100 & 319 & - \\
\hline 12 & Morada Nova & Morada Nova & $\mathrm{CE}$ & 3.000 & 410 & - \\
\hline 13 & Ema & Iracema & $\mathrm{CE}$ & 120 & 81 & - \\
\hline 14 & Jaguarana & Jaguarana & $\mathrm{CE}$ & 280 & 144 & - \\
\hline 15 & Curu Recuperação & Pentecostes & $\mathrm{CE}$ & 1.200 & 1.131 & 04 \\
\hline 16 & Curu Paraipaba & Curu & $\mathrm{CE}$ & 3.600 & 546 & - \\
\hline 17 & Forquilha & Sobral & $\mathrm{CE}$ & 420 & 410 & - \\
\hline 18 & Ayres de Souza & Sobral & $\mathrm{CE}$ & 350 & 176 & - \\
\hline 19 & Quixabinha & Mauriti & $\mathrm{CE}$ & 200 & 179 & - \\
\hline 20 & Fidalgo & Simplício Mendes & $\mathrm{CE}$ & 290 & 191 & - \\
\hline 21 & Gurgueia & Cristino Castro & $\mathrm{CE}$ & 675 & 489 & - \\
\hline 22 & Caldeirão & Piripiri & $\mathrm{CE}$ & 673 & 575 & - \\
\hline 23 & Lagoa do Piauí & Luzilândia & $\mathrm{CE}$ & 1.272 & 821 & - \\
\hline
\end{tabular}

A Tabela II contém algumas informações sobre os sete perimetros de irrigação selecionados, de acordo com os parâmetros estabelecidos na metodologia deste trabalho.

TABELA II

Algumas características dos açudes irrigados do semi-árido, DNOCS. Áreas selecionadas - 1979

\begin{tabular}{clccccl}
\hline $\begin{array}{c}\text { No } \\
\text { de } \\
\text { Ordem }\end{array}$ & $\begin{array}{c}\text { Nome } \\
\text { do } \\
\text { Perímetro }\end{array}$ & Estado & $\begin{array}{c}\text { No } \\
\text { de } \\
\text { Colonos }\end{array}$ & $\begin{array}{c}\text { Anos } \\
\text { de } \\
\text { Operação }\end{array}$ & $\begin{array}{c}\text { Tipos } \\
\text { de } \\
\text { Irrigação }\end{array}$ & $\begin{array}{c}\text { Localização } \\
\text { da } \\
\text { Moradia }\end{array}$ \\
\hline 01 & Cachoeira II & PE & 36 & 06 & Aspersão & Lote \\
02 & Boa Vista & PE & 27 & 06 & Gravidade & Lote \\
03 & Moxotó & PE & 151 & 02 & Gravidade & Vila \\
04 & Sumé & PB & 46 & 09 & Gravidade Vila/Lote \\
05 & São Gonçalo & PB & 260 & 06 & Gravidade Vila \\
06 & Curú-Recuperação & CE & 153 & 04 & Gravidade Vila \\
07 & Itans/Sabugi & RN & 73 & 05 & Gravidade Vila \\
\hline
\end{tabular}

(*) - De acordo com os valores dos salários mínimos na época e em 1984. 
Das 25 pessoas infectadas por $S$. mansoni, 16 foram consideradas casos autóctones. Nenhuma delas nasceu dentro dos limites dos perímetros de irrigação. Nove das pessoas parasitadas nasceram em sítios localizados na periferia do perímetro de São Gonçalo. As demais pessoas, tanto no perímetro de São Gonçalo como no de Moxotó, nasceram em zonas não-endêmicas de esquistossomose. A distribuição por grupos de idade mostra que a grande maioria dos casos autóctones ocorre em indivíduos com 18 anos ou menos. Apenas três casos são assinalados em indivíduos acima do grupo de 18 anos (Tabela III).

A única espécie de Biomphalaria encontrada nos períme. tros foi $B$. straminea.

\section{TABELA III}

Casos au tóctones de S. mansoni nos perimetros irrigados de São Gonçalo (PB) e de Moxotó (PE), 1979.

\begin{tabular}{llllll}
\hline $\begin{array}{c}\text { No de } \\
\text { Ordem }\end{array}$ & Iniciais & Perímetros & $\begin{array}{c}\text { Idade } \\
\text { (anos) }\end{array}$ & \multicolumn{1}{c}{$\begin{array}{c}\text { Local de } \\
\text { Nascimento }\end{array}$} & $\begin{array}{c}\text { Tempo de } \\
\text { Permanência no } \\
\text { Perímetro (anos) }\end{array}$ \\
\hline 01 & F.D. & S. Gonçalo & 18 & Sítio & 05 \\
02 & J.M. & S. Gonçalo & 15 & Gravatá (PE) & 03 \\
03 & J.P. & S. Gonçalo & 07 & Sítio & 01 \\
04 & J.H. & S. Gonçalo & 11 & Sítio & 04 \\
05 & M.N. & S. Gonçalo & 10 & Nazarezinho-PB & 01 \\
06 & D.V.S. & S. Gonçalo & 10 & Sítio & 04 \\
07 & I.S. & S. Gonçalo & 12 & Gravatá (PE) & 03 \\
08 & A.L. & S. Gonçalo & 07 & Sítio & 04 \\
09 & M.S. & S. Gonçalo & 10 & Flores (RN) & 04 \\
10 & M.E. & S. Gonçalo & 33 & Sítio & 04 \\
11 & M.G. & S. Gonçalo & 11 & Nazarezinho-PB & 04 \\
12 & G.L. & S. Gonçalo & 14 & Sítio & 04 \\
13 & M.A. & S. Gonçalo & 17 & Sitio & 04 \\
14 & F.M. & S. Gonçalo & 12 & Sítio & 04 \\
15 & K.B.S. & Moxotó & 13 & Itaíba (PE) & $011 / 2$ \\
16 & M.J.S. & Moxotó & 21 & S. Bento do Una (PE) & 01 \\
\hline
\end{tabular}

\begin{tabular}{|c|c|c|c|c|c|c|c|}
\hline \multicolumn{6}{|c|}{$\begin{array}{l}\text { Principais Culturas } \\
\text { Classificadas em 1ạ, 2ạ, ou 3ạ opção }\end{array}$} & \multicolumn{2}{|c|}{$\begin{array}{l}\text { Renda média obtida } \\
\text { pelo Colono }(\mathrm{Cr} \$)\end{array}$} \\
\hline Algodão & Arroz & Banana & Feijão & Milho & Tomate & 1979 & Projeção p/1984* \\
\hline - & - & $2 \mathrm{a}$ & - & - & 19 & 90.000 & 6.606 .000 \\
\hline - & - & $2 \stackrel{a}{a}$ & - & - & 19 & 40.000 & 2.936 .000 \\
\hline - & - & $2 \mathrm{a}$ & - & $3 a$ & $1 \stackrel{a}{a}$ & 50.000 & 3.670 .000 . \\
\hline - & - & $2 \mathrm{a}$ & - & - & 19 & 93.520 & 6.864 .368 \\
\hline - & $3 a$ & $2 a$ & - & - & $1 \stackrel{a}{a}$ & 56.000 & 4.110 .400 \\
\hline $2 \mathrm{a}$ & - & 1 a & $3 a$ & - & - & 48.827 & 3.583 .901 \\
\hline- & $3 a$ & 19 & - & - & $2 \mathrm{a}$ & 50.000 & 3.670 .000 \\
\hline
\end{tabular}


* Texto recente para referencias bibliográficas

\section{COMENTÁRIOS}

Os resultados do presente trabalho são baseados em extenso levantamento inicial realizado em 23 perímetros de irrigação.

Pelos resultados aqui obtidos, de 9.044 exames de fezes realizados, 25 foram positivos para $S$. mansoni. Apenas em quatro perímetros de irrigação foram assinaladas pessoas in. fectadas, sendo que a maior concentração de casos está no perímetro de São Gonçalo, Estado da Paraíba. A presença da endemia esquistossomótica neste perímetro já era conhecida da SUCAM que aí vem trabalhando com a finalidade de controlar a infecção ${ }^{2}$.

Moxotó, com dois casos autóctones de esquistossomose, pela primeira vez assinalados, passa a ser considerado como o segundo perímetro de irrigação do DNOCS onde a esquistossomose é presumivelmente endêmica.

É de interesse assinalar que a distribuição etária dos casos autóctones de esquistossomose indica que a endemia é de introdução recente nos dois perímetros de irrigação.

$B$. straminea, a única espécie de Biomphalaria encontrada nas áreas investigadas, é considerada, do ponto de vista biológico, como transmissora menos importante do que $B$. glabrata. Entretanto, aquela espécie, do ponto de vista epidemiológico, é capaz de manter a parasitose em niveis endêmicos muito elevados, pelo menos nas regiões úmidas do Nordeste brasileiro ${ }^{1}$. Acentue-se que este fato, isoladamente, não justifica o comportamento epidemiológico da esquistossomose nas áreas de irrigação. Este assunto será melhor discutido no último trabalho desta série.

A experiência mundial nas regiões endêmicas do mundo mostra claramente que a irrigação tem sido importante fator de dispersão e agravamento da esquistossomose, tanto mansônica quanto hematóbica ${ }^{4}$ *

No trabalho que se seguirá a este, os resultados dos estudos realizados nus sete perímetros selecionados, localizados nos Estados de Pernambuco, Paraíba e Ceará, serão analisados e comentados com mais profundidade.

Uma conclusão geral pode, entretanto, ser tirada. A esquistossomose não apresenta, até o momento, no Nordeste semi-árido, êxito comparável ao que vem ocorrendo no restante das regiōes endêmicas do mundo onde sistemas de irrigação foram implantados.

Mesmo em perímetros que na época da realização deste trabalho tinham 10 ou mais anos de operação, os resultados mostram que a esquistossomose não se estabeleceu. Em Lima Campos (CE) e Caldeirão (PI), ambos com 10 anos de operação, nenhum caso da infecção foi assinalado. $O$ mesmo ocorreu com Sumé (PB), com 12 anos, e Morada Nova (CE) com 13 anos de operação. 
Pereira da Costa ${ }^{5}$, em estudo epidemiológico realizado no período de 1970 a 1975, no antigo Núcleo Colonial de Barreiros (hoje coberto pelas águas da represa de Itaparica), não encontrou nenhum caso autóctone de esquistossomose, não obstante as condições epidemiológicas favoráveis. Esse Núcleo vinha funcionando desde 1945.

As razões do comportamento da esquistossomose mansônica nos perímetros de irrigação e nas grandes barragens do Nordeste semi-árido serão analisadas e discutidas no último trabalho desta série.

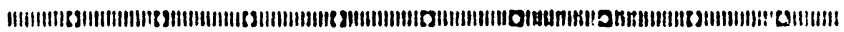

Nesta primeira série de um conjunto de três trabalhos, foram estudados, do ponto de vista epidemiológico, 23 perimetros de irrigação do Departamento Nacional de Obras Contra as Secas (DNOCS), com vistas à determinação da presença de esquistossomose. Os resultados indicaram que, além do perímetro de São Gonçalo, PB londe a esquistossomose já era conhecida), casos autóctones da doença foram encontrados no perimetro de Moxotó, PE.

\section{REFERÊNCIAS BIBLIOGRĀFICAS}

1. BARBOSA, F. S. Aspects of the ecology of the intermediate hosts of Schistosoma mansoni interfering with the transmission of bilharziasis in Northeastern Brazil. In: Ciba Foundation Symposium on Bilharziasis, Cairo, 1962. p. 23-25.

2. CAMARGO, S. \& REPUBLICANO, J.A.A. Esquistossomose em áreas de irrigação. In: Situação e perspectivas do controle das doenças infecciosas e parasitárias. Brasília, UNB, 1981. p. 57-66 (Cadernos da UNB).

3. CNPq. Epidemiologia e controle da esquistossomose e o nordeste semi-árido. Relatório de um grupo de trabalho, Brasília, 1978. 77 p.

4. HUNTER, J.M.; REY, L. \& SCOTT, D. Man-made lakes and man-made diseases. Soc. Sci. Med. 16: 1127.45. 1982.

5. PEREIRA DA COSTA, D. Estudo epidemiológico da esquistossomose em áreas de irrigação do sèrtão de Pernambuco. Rev. FSESP, $23:$ 9-14, 1978. 